\title{
EVASÃo ESCOLAR NA 1a SÉRIE DO ENSINO MÉDIO: O CASO DE JoaÇaba, Santa Catarina
}

\section{SCHOLAR DROPPING OUT IN THE 1ST GRADE IN HIGH SCHOOL: the Case in JoaÇaba, Santa Catarina}

\author{
Douglas Branco de Camargo \\ Mestre em Educação pela Universidade do Oeste de Santa Catarina (UNOESC). Docente na Faculdade \\ Avantis, Balneário Camboriú, SC - Brasil \\ douglascamargo998@hotmail.com \\ Mônica Piccione Gomes Rios \\ Doutora em Educação. Professora Titular do Programa de Pós-Graduação em Educação da Pontifícia \\ Universidade Católica de Campinas (PUCAMP), Campinas, SP - Brasil. \\ monica.rios@puc-campinas.edu.br
}

Resumo: Este artigo resulta de pesquisa que investiga açôes políticas e pedagógicas relacionadas à evasão escolar na $\mathrm{I}^{\mathrm{a}}$ série do Ensino Médio, no município de Joaçaba, Santa Catarina, envolvendo coleta de dados na GERED ${ }^{1}$. De abordagem qualiquantitativa, problematiza como a evasão escolar é enfrentada, considerando, na análise dos dados, a existência da dinâmica entre realidade objetiva e sujeito subjetivo. Os resultados apontam para um cenário que necessita de políticas públicas de mudanças estruturais e que se fundamentem em novos olhares e açóes sobre a realidade escolar, particularmente quanto à formação docente, juventude contemporânea e infraestrutura escolar, vistos como elementos fundamentais para o desenvolvimento da educação com qualidade social.

Palavras-chave: Ensino Médio. Evasão Escolar. Juventude.

Aвstract: This article is the result of the research that investigates political and pedagogical actions related to the scholar dropping out of the Ist grade of the High School in the city of Joaçaba, Santa Catarina. The research deals with how the scholar drop out is handled. The qualitative/quantitative approach considers the existence of the dynamic between objective reality and subjective subject, involving data collection from GERED and from scholar institutions, interviews and analyses. The results point to a scenery that needs public policies of structural changes and new views and actions on scholar institutions, teachers' formation, attention to the youth and to infrastructure and everybody's permanent modernization to the development of education of and with social quality.

Keywords: High School. Scholar Dropping Out. Youth. 


\section{Introduçáo}

Esta pesquisa considerou o estudo de Neri (2009), que demonstra o impacto da educação na qualidade de vida e renda dos indivíduos, corroborando a importância da educação de/com qualidade social para todos na conjuntura brasileira. Os dados trazidos pelo pesquisador impóem a reflexão sobre a situação preocupante da evasão escolar, pois apontam que, em 2006, no Brasil, I7,8 \% da populaçáo de I5 a I7 anos, que deveria estar cursando o ensino médio caso não houvesse atraso escolar, estavam fora da escola em decorrência de evasão. Eles expressam a exclusão do adolescente/jovem $^{2}$ da instituição escolar e das relaçóes que ela propicia, prefigurando sujeitos que perderam a oportunidade de vislumbrar na educação um investimento importante e necessário, posto que a construção do conhecimento e a conquista diploma do Ensino Médio são essenciais para a formação do cidadão e sua inserção no mundo do trabalho.

De acordo com o Instituto Nacional de Estudos e Pesquisas Anísio Teixeira (Inep), em 2009 o estado de Santa Catarina somou 237.358 mil matrículas no Ensino Médio. Dessas, 1.907 mil foram na rede federal de ensino, 202.210 mil na estadual, 793 na municipal e 32.448 mil na rede privada; I II.I97 mil delas foram efetuadas no período matutino, 33.894 mil no vespertino e 92.267 mil no noturno. Para atender a essa demanda de matrículas no ensino médio, 858 instituições escolares ofereciam esse nível de ensino no estado, divididas em 06 instituiçôes federais, 637 estaduais, 09 municipais e 206 privadas.

Considerado ainda o universo total de matrículas no estado e o mesmo ano de 2009, tem-se que 16.063 mil deixaram de frequentar a instituição escolar no período, totalizando uma taxa de evasão de 6,76\%. Os índices expressam 53 desistências na rede federal de ensino, $15.8 \mathrm{I} 3 \mathrm{mil}$ na estadual, I04 nas redes municipais e 93 na privada. Os dados demonstram que o número de matrículas no Ensino Médio no estado representa um total de 92.08I mil na $\mathrm{I}^{\mathrm{a}}$ série, 74.246 na $2^{\mathrm{a}}, 66.326$ na $3^{\mathrm{a}}, 2.449$ na $4^{\mathrm{a}}$ série, quando no ensino profissionalizante, e 2.256 no ensino náo seriado. Observamos que os índices de evasão no Ensino Médio no estado, durante o período de recorte da pesquisa, são relevantes. De modo muito claro, a evasão escolar na $\mathrm{I}^{\mathrm{a}}$ série representa um índice alto, o que caracteriza um 
gargalo. É necessário ressaltar que, em 2007, o Ensino Médio no estado possuía 8.164 mil turmas, sendo $3.074 \mathrm{mil} \mathrm{de} \mathrm{I}^{\mathrm{a}}$ série.

Em relação ao município de Joaçaba, Santa Catarina, conforme os dados fornecidos pela Gerência de Educação (GERED) e pelas instituiçóes escolares públicas que oferecem o nível médio de ensino, em 2007 foram registradas 385 matriculas na $\mathrm{I}^{\mathrm{a}}$ série, entre os períodos diurno e noturno. Desse total de matriculas, 89 adolescentes/jovens evadiram, totalizando um índice de 23,II\% naquele ano. Há ainda que considerar os alunos que concluíram o Ensino Fundamental e não ingressaram no Médio, pois de acordo com os dados fornecidos pelas instituiçôes escolares muitos entre eles não o fizeram, conformando a pirâmide educacional que abrevia a trajetória de um significativo número de estudantes.

Diante desses dados surgem inquietaçóes, questionamentos e hipóteses que indicam a necessidade de políticas públicas que mudem a estrutura das instituiçôes escolares, particularmente quanto à formação inicial e continuada dos profissionais da educação, e que mobilizem os envolvidos no processo do ensino, para garantir melhores resultados nessa última etapa da Educação Básica. Como homens e mulheres partícipes da sociedade e profissionais da educação, impóe-se nosso engajamento na reversão desse cenário. Nessa perspectiva, urge que a necessidade de a instituição escolar se aproximar dos interesses da sociedade, dos sujeitos, oportunizando o desenvolvimento da criatividade, preponderantemente atuando para a formação de cidadãos e contribuindo com sua formação crítica por meio do processo de ensino e aprendizagem escolar, na ação-reflexão sobre os saberes eruditos historicamente produzidos e socialmente acumulados e trabalhando com os saberes sociais da atualidade. Para alcançarmos esse intento, faz-se importante considerar que a evasão escolar é um problema que existiu no passado e existe no presente, sendo fundamental que formuladores e gestores de políticas públicas, profissionais da educação e sociedade se articulem para a superação do cenário de evasão escolar que reflete uma lógica excludente para o futuro.

A pesquisa da qual se originou este artigo teve como objetivo investigar as açôes, nos âmbitos político e pedagógico, relacionadas à evasão escolar dos alunos matriculados na $\mathrm{I}^{\mathrm{a}}$ série do Ensino Médio, entre os anos de 2007 e 2009, no município de Joaçaba, evidenciando que os estudos em educação estão na pauta de preocupação da sociedade joaçabense e de- 
monstrando que há pesquisas interessadas em investigar os problemas que ocorrem nas instituiçóes escolares locais, com vistas a desencadear processos de intervenção na perspectiva defendida por Paulo Freire (I996, p. 29): "Pesquiso para constatar, constatando, intervenho, intervindo educo, e me educo. Pesquiso para conhecer o que ainda não conheço e comunicar ou anunciar a novidade."

A relevância da pesquisa reside em dar a conhecer o contexto das instituiçóes escolares que ofertam Ensino Médio, seus desafios e superaçôes e, sobretudo, salientar o compromisso com o jovem do século XXI, subsidiando essas instituições, seus profissionais e a sociedade com um estudo epistemológico sobre o complexo problema da evasão escolar, na perspectiva de investigação e produção do conhecimento novo sobre o tema. Segundo Patto (1996), a evasão/fracasso escolar interfere na formação pessoal, humana e impede a formação profissional. Trata-se, portanto, de um problema social, o que nos mobilizou a investigar e conhecer esse fenômeno, avaliá-lo e pensar estratégias para seu enfrentamento no âmbito local.

A abordagem predominante na pesquisa foi qualitativa, entretanto, não desprezamos os dados passíveis de quantificação. As metodologias qualitativa e quantitativa contribuíram para investigar o problema de pesquisa e realizar a análise das questóes de entrevista, fundamentadas no aporte teórico que a embasa. Para Gatti (2004), a pesquisa quantitativa pode favorecer a compreensão de um problema, principalmente quando combinada à pesquisa qualitativa. A fim de conhecer a realidade dos sujeitos investigados, buscamos estruturá-la em dois procedimentos. O primeiro trata da pesquisa quantitativa, com vistas a identificar os índices e as principais causas da evasão escolar na I ${ }^{a}$ série do Ensino Médio das escolas públicas de Joaçaba entre os anos de 2007 e 2009 . O segundo procedimento diz respeito à entrevista semiestruturada como instrumento de coleta de dados mais adequado às pesquisas sociais. As entrevistas realizadas foram individuais e semiestruturadas, com uso, pelo entrevistador, de um roteiro de questóes que cobria os objetivos da investigação, ou seja, por meio de suas respostas os informantes revelam suas representações sobre a realidade, suas experiências, percepçóes e concepçóes básicas. As entrevistas abarcaram 02 gestores escolares (GE), 02 coordenadores pedagógicos (CP), 06 professores (P) e or gestor da GERED (GR). Para realiza-las, foram visita- 
das as instituiçóes escolares e a GERED, para que nos apropriássemos da representação dos sujeitos entrevistados. $\mathrm{O}$ instrumento abordou o registro de informaçóes sobre os aspectos relacionados ao ambiente escolar e à gestão, sobre professores e demais funcionários, além de questionar os termos fixados nos documentos escolares.

No que se refere aos procedimentos qualitativos de análise dos dados coletados nas entrevistas, eles foram sistematizados por meio da identificação e classificação das categorias mais significativas. A análise empreendida revelou as representaçóes dos entrevistados sobre a temática da evasão naquele universo particular, as divergências e convergências entre os envolvidos.

O processo de disseminação da escolarização tem produzido uma série de transformaçôes na nossa sociedade, pois

Ao mesmo tempo que a escola se abre a novos contingentes de alunos, ela se vê obrigada a responder a essa demanda sem estar preparada para uma mudança qualitativa que lhe permita lidar com os anseios desse novo tipo de ator. Estas transformaçóes colocam em crise a oferta tradicional da educação, trazendo consigo sintomas de fracasso. (ABRAMOVAY; CASTRO, 2003, p. 34)

Para esses autores, chegar ao Ensino Médio é um prêmio, especialmente para as classes populares. Indicam ainda que "a única forma de pensar uma mudança que possibilite uma relativa ascensão social é a adequação do espaço escolar às reais necessidades da clientela juvenil." (id. ib.) Os problemas e as angústias referentes às instituiçôes escolares e aos adolescentes/jovens têm sido a preocupação de muitos campos do conhecimento, e é num desses campos que esta pesquisa se insere, avançando na compreensão da instituição escolar em consideração às representaçóes dos atores que a vivenciam e que fazem sua história, mesmo que, muitas vezes, desprovidos de autonomia.

Nesse sentido, esta pesquisa pretende contribuir de forma consistente com a academia, a educaçáo e a sociedade, dado que configura uma investigação de campo dos processos pedagógicos escolares que demarcam a instituição escolar como ambiente de produção do pensar. 


\section{Educação básica: o Ensino Médio}

O direito à educação básica é garantido pela Constituição Federal de 1988, sendo intenção da política educacional pública brasileira expressa na Lei de Diretrizes e Bases da Educação Nacional (LDB 9394/96), aprovada em 17 de dezembro de 1996 e promulgada em 20 de dezembro de 1996, com publicação no Diário Oficial da União de 23 de dezembro de 1996.

No contexto da LDB, o Ensino Médio é a terceira e última etapa da Educação Básica, sendo uma modalidade de ensino que possui, no mínimo, três anos e tem como clientela sujeitos de, no mínimo, quatorze anos. Torna-se gradativamente obrigatório e gratuito, contudo, ainda se caracteriza como um nível de ensino de difícil enfrentamento, especialmente pelo legado histórico de indefinição sobre sua finalidade, diferentemente do Ensino Fundamental de nove anos, que possui uma proposta curricular organizada com base na oferta de conteúdos comuns e unitários. Na Lei de Diretrizes e Bases o Ensino Médio é um nível de ensino intermediário, situado entre o fundamental e o superior, que precisa definir sua finalidade, situação essa que tem sido objeto de indagaçóes de pesquisadores como Frigotto, Ciavatta e Ramos (2005), Küenzer (2007), entre outros.

Compreender o Ensino Médio como etapa da Educação Básica e passo fundamental no processo de formação e transformação educativa dos adolescentes/jovens cidadáos implica reconhecer que esse nível de ensino assume muitos significados e necessita de uma definição estrutural que contemple esse processo de formação dessa importante parcela da população brasileira. Ao se referir à população jovem do país, Lassance (2005, p. 74) explica que:

O jovem brasileiro corresponde a cerca de $20,13 \%$ da população do país. São aproximadamente 34,I8 milhôes de jovens, em uma população estimada pelo último Censo em I69,79 milhôes. (IBGE, 2002). Uma estimativa corrigida em 200I, aplicada à taxa de crescimento da população, nos leva a considerar a existência de aproximadamente 17,77 milhóes de jovens de I5 
a 19 anos e Io milhões de jovens de 20 a 24 anos. Estes contingentes são, respectivamente, I0,31\% e 9,8\% da populaçấo total.

Desses adolescentes/jovens, a maior parte se encontra nas áreas urbanas e precisa inserir-se no mercado de trabalho e de consumo, o que estabelece uma nova relação entre a necessidade de trabalhar e o acesso a melhores oportunidades, e gera expectativas sobre a educaçáo dos que estão cursando o Ensino Médio. No entanto, para o governo, também um refém das dinâmicas comandadas pelo capital, a expansão desse nível de ensino necessita de recursos didático-pedagógicos apropriados a essas demandas, conhecimento de métodos e metodologias necessários para um melhor atendimento desses adolescentes/jovens na instituição escolar e infraestrutura adequada, assim como, e principalmente, investimentos em qualificação de profissionais da educação que compreenda a formação inicial articulada à formação continuada.

Segundo Frigotto, Ciavatta e Ramos (2005), o descaso do Estado para com espaços físicos e financiamento que atendam às demandas específicas dos estudantes do Ensino Médio é significativo. Esse nível de ensino possui, na contramão da legislação, um conteúdo curricular desarticulado da realidade social e de baixa qualidade para as finalidades e objetivos presentes nos documentos oficiais. Destaca-se ainda sua intencionalidade mal definida quanto ao aprofundamento dos conhecimentos adquiridos no Ensino Fundamental e à preparação para o trabalho e a cidadania, por meio da construção da autonomia intelectual e moral do educando.

De acordo com o MEC/INEP/SAEB (2004), o Ensino Médio apresentou um crescimento de $84 \%$ nos últimos dez anos, que se expressa num número de matrículas bastante significativo. Tais valores indicam que é preciso construir coletivamente um projeto político-pedagógico comprometido com as necessidades sociais e culturais da populaçáo local e, ao mesmo tempo, atenção aos acontecimentos globais, com vistas à transformação da realidade.

Para Abramovay e Castro (2003), muitos adolescentes/jovens revelam que as instituiçóes que oferecem o Ensino Médio constituem um espaço distante de seus interesses pessoais e, dessa forma, a escola acaba sendo um local de conflitos e de realidade excludente. Para as autoras, as instituiçóes escolares necessitam utilizar flexibilidade, foco nas necessi- 
dades de seu público adolescente/jovem e estímulo ao desenvolvimento pessoal e coletivo dos sujeitos, aliados a um currículo que se materialize na escola, para trabalhar o desenvolvimento integral dos sujeitos.

A mudança e a melhora da qualidade de ensino colocar-se-ão, assim, não apenas no terreno mais comum de pôr em dia os conhecimentos que o currículo compreende para acomodar melhor a evolução da sociedade, da cultura, ou para responder a igualdade de oportunidades inclusive, mas como instrumento para incidir na regulação da ação, transformar a prática dos professores, liberar as margens da atuação profissional etc. (SACRISTÁN, 1998, p. 53)

A formulação de políticas públicas para o Ensino Médio necessita compreender o fenômeno dos adolescentes/jovens na contemporaneidade para direcionar seus objetivos e metas, garantindo a todos os cidadáos o acesso e a permanência a um ensino médio de qualidade sociocultural e o sucesso desses adolescentes/jovens. Segundo Arroyo (s/d), citado por Rios (200I, p. 74-75), a qualidade sociocultural do ensino,

[...] passa pela 'construção de um espaço público, de reconhecimento de diferenças, dos direitos iguais nas diferenças' e, mais especificamente na contemporaneidade, pela 'renovação dos conteúdos críticos e da consciência crítica dos profissionais', pela 'resistência a uma concepção mercantilizada e burocratizada do conhecimento', pelo 'alargamento da função social e cultural da escola e intervenção nas estruturas excludentes do velho e seletivo sistema escolar.

A partir disso, a compreensão sobre o Ensino Médio exige disponibilidade para pensarmos uma realidade nacional marcada pela exclusão social, que necessita ser revertida. Nesse processo, é fundamental considerarmos a importância de conceber o homem como um sujeito ativo que cria seu meio, sua realidade e, ao mesmo tempo, é produto desse meio, num processo dialético construído pelos seus ao longo da história. 


\section{Evasão escolar}

A evasão escolar é um dos relevantes temas que historicamente faz parte dos debates e reflexôes na esfera da educação pública brasileira e que, infelizmente, ainda nos dias de hoje, ocupa um importante espaço no cenário da educação nacional. Segundo Freire (I996), o combate tão atual contra os alarmantes índices de reprovação, que acabam por ocasionar a expulsão de alto número de crianças da instituiçãao escolar, não passa de um fenômeno que a ingenuidade ou a malícia de muitos educadores denominam evasão escolar. Para o autor, esses conceitos são expressóes da ideologia dominante que levam a que as instâncias de poder, antes mesmo de assegurar-se das verdadeiras causas do intitulado 'fracasso escolar', imputem toda a culpa aos educandos. Para Freire (I996), ao longo do tempo as instituiçóes escolares desempenharam seu papel social baseadas no pensamento influenciado pela teoria da evolução natural, selecionando os mais 'aptos' a trilharem os caminhos do sucesso e reproduzindo, no caso dos menos 'aptos', a cultura da excludência. E, nesse contexto, as teorias racistas foram usadas para justificar diferenças individuais e desigualdades sociais, na medida em que corroboravam os pressupostos da aptidão e do inatismo para explicar as diferenças de rendimento dos alunos.

Apesar de tantas tentativas de encontrar culpados para tal situação, problemas de evasão e de fracasso escolar continuam de forma alarmante e persistente. De acordo com Arroyo (2000, p. I3),

A consciência do direito à educação básica universal avançou, porém não conseguimos que a escola se estruturasse para garantir esse direito, ela continua como instituiçâo seletiva e excludente. A escola como instituição - não com boas vontades de seus mestres - mantém a mesma ossatura rígida e excludente. Continua aquela estrutura piramidal, preocupada apenas com o domínio seriado e disciplinar de um conjunto de habilidades e saberes. A ultrapassagem de domínios preestabelecidos em cada disciplina e em cada série é pré-condição para a manutenção ou a perda irrecuperável do direito de uma experiência sociocultural formadora. 
Diante do cenário da evasão escolar e a consequente reprovação como forma de fracasso escolar, surgem no Brasil 'perspectivas e propostas educacionais' para a aceleração da aprendizagem, projetos de adequação/ correção idade/série, organização escolar por ciclos e classes aceleradas, todas voltadas para resolver o problema do fracasso escolar; no entanto, os índices de evasão não diminuem. Reafirmando a própria (des)organização da educação nacional, Mantovanini (200I) nos faz refletir sobre os processos pedagógicos de ensino e aprendizagem, que compreendem três elementos muito importantes: o professor, o conteúdo e o sujeito que aprende. E se o aluno não aprende, é sinal de que os outros dois elementos também falharam no processo.

Encontrar as causas para o fenômeno da evasão escolar não é tarefa fácil, requer o entendimento e a compreensão de que são múltiplos fatores que influenciam para que o sujeito abandone da escola. A evasão escolar pode ocorrer devido a diversas situaçóes e a distintas condiçóes, internas ou externas ao indivíduo. Considerando as condiçôes internas de estudantes adolescentes/jovens, enfatiza-se o desenvolvimento cognitivo, as questóes de afetividade, emoção, motivação e os relacionamentos desses sujeitos. Entre as situaçóes exteriores mais percebidas podemos citar as condiçóes de ordem social e econômica das famílias dos estudantes, determinando a necessidade do trabalho para obtenção de renda, e as condiçôes oferecidas pelas instituições quanto a infraestrutura física e pedagógica e a gestão, profissionais despreparados e desmotivados, além da formação inicial e continuada dos professores ser reconhecidamente falha.

\section{O caso de Joaçaba, Santa Catarina}

No decorrer da pesquisa, as entrevistas com questôes semiestruturadas foram utilizadas para ouvir diversos sujeitos vinculados à educação escolar: gestor regional (GR), gestores escolares (GE), coordenadores pedagógicos $(\mathrm{CP})$, supervisores pedagógicos $(\mathrm{SP})$ e professores $(\mathrm{P})$, na busca de compreender o significado que atribuem ao Ensino Médio, com foco nas dimensóes política e pedagógica relacionadas à evasão escolar dos alunos matriculados na $I^{a}$ série do Ensino Médio, entre os anos de 2007 e 2009, no município de Joaçaba, Santa Catarina. Por intermédio dessas ques- 
tôes, procuramos criar as condiçóes para entender o significado do Ensino Médio e verificar quais as ações político-pedagógicas promovidas no âmbito das instituiçóes escolares, bem como as açôes emanadas da gestáo.

Assim, os dados foram avaliados de forma qualitativa, sem confirmação de nenhuma hipótese preestabelecida, na busca da compreensão e interpretação conforme as categorias foram surgindo no trabalho empírico.

Ao serem questionados sobre a concepção que possuem sobre o Ensino Médio, os participantes das entrevistas destacaram, com ênfase, que esse nível de ensino necessita oferecer preparação para a educação superior, para o exercício profissional e para o trabalho; aquisição de conhecimentos e formação do cidadão participativo. Apontaram ainda a base para a escolha da profissão e do trabalho, concepção teórica presente na proposta curricular, concepção prática do cotidiano de sala de aula, desenvolvimento profissional e humano e defasagem de conhecimentos.

Os educadores entrevistados demonstraram ciência da importância do Ensino Médio na formação do cidadâo participativo e na preparação para o exercício profissional e para o trabalho no mundo contemporâneo, consoante com os documentos oficiais. A esse respeito, Berger Filho ${ }^{3}$ (I999, p. I3) expressa:

O Ensino Médio no Brasil está mudando. A consolidação do estado democrático, as novas tecnologias e as mudanças na produção de bens, serviços e conhecimentos exigem que a escola possibilite aos alunos integrarem-se ao mundo contemporâneo nas dimensões fundamentais da cidadania e do trabalho.

Ao nos referirmos às mudanças do Ensino Médio preconizadas pela LDB de 1996, consideramos, a partir das entrevistas, que gestores públicos, instituição escolar e profissionais da educação, além da sociedade, encontram desafios ao realizar trabalhos que desenvolvam nos alunos suas competências básicas. Os profissionais deparam com dificuldades na formação do cidadáo, para que este saiba conviver democraticamente e esteja preparado para a integração social e a socialização de saberes na vida e no mundo profissional e do trabalho, conforme observamos na resposta do GR: "Que o aluno se torne um cidadáo, promova mudanças no meio em 
que vive, através do conhecimento, e que ele tenha o conhecimento necessário para a aprovação e para a vida."

Ao serem convidados a refletir sobre os principais desafios do Ensino Médio, os sujeitos entrevistados sublinharam o acesso e a permanência, o interesse do adolescente/jovem, a participação e apoio da família, a articulaçáo entre escola e comunidade, as dificuldades de aprendizagem e a infraestrutura, ao lado da diversidade em sala de aula, dos recursos de desenvolvimento humano e profissional, da relação teoria/prática, do aprofundamento de conteúdos. Alguns depoimentos pontuam tais desafios:

O primeiro é que o aluno entre no ensino médio e permaneça com sucesso [...] Também gostaríamos que o ensino fosse tão bom e tão atraente que o aluno não tivesse vontade de sair. (GR) Mantê-los na escola. Manter esses alunos na escola é o que mais nós enfrentamos como dificuldades. ( $\left.\mathrm{CP}_{2}\right)$

O desafio é ele permanecer na escola. ( $\left.\mathrm{P}_{5}\right)$

Essas manifestaçôes demonstram a necessidade de democratização da instituição escolar como espaço institucional de efetivo exercício do processo de gestão democrática. Nas próprias entrevistas, em diversos momentos, conseguimos observar a preocupação dos sujeitos com a questão da infraestrutura deficitária da instituição escolar e da não atração do aluno pelo ambiente desta. São muitos os motivos, mas a situação mais latente que observamos é que a instituição escolar precisa conhecer seu público, alunos adolescentes/jovens do Ensino Médio, pois esse conhecimento, aliado às condiçôes de trabalho, que também necessitam ser melhoradas, poderão ressignificar as vivências nesse espaço.

No referente ao interesse dos adolescentes/jovens, os participantes da pesquisa insistiram que constitui elemento importante a ser considerado quando se reflete sobre os desafios do ensino médio, assim traduzidos: "O maior desafio é fazer com que o aluno tenha interesse de permanecer na sala de aula.” (G2) Para os entrevistados, os adolescentes/jovens das instituiçóes escolares que oferecem o Ensino Médio não têm interesse na escola, frequentam-na por obrigaçáo, seja legal seja pela autoridade dos pais quando esses ainda participam da educação dos filhos. 
Para o estado de Santa Catarina, que tem na consolidação da sua proposta curricular ${ }^{4}$ um marco importante na educaçáo pública catarinense, consistência e relevância pedagógica dos conteúdos e do currículo validam-se como instrumento elaborado pelo trabalho coletivo de educadores e especialistas. Nesse sentido, a Secretaria Estadual de Educação articulou açôes, até 2005 , de construção de um novo documento, de trabalho coletivo, somando esforços na busca de atender às demandas da nova sociedade; assim, provocaram a necessidade da produção e publicação de material denominado Estudos Temáticoss.

Percebemos, no decorrer da análise dos próprios depoimentos, que as escolas estão buscando cativar seus alunos adolescentes/jovens para fins de mantê-los na escola e reduzir a evasão, realizando diversas atividades motivadoras e de estímulo à continuidade dos estudos, com atençáo para as realidades específicas. Consideramos que, no enfrentamento a esse desafio, gestores, professores e profissionais da educação buscaram formas de transformar a instituição escolar em um ambiente atrativo, estimulante e envolvente. Diante disso, reputamos de fundamental importância que os gestores e suas equipes busquem conhecer continuadamente a realidade da comunidade escolar para efetivar o seu trabalho.

O grupo de entrevistados enfatizou a articulação da escola com a comunidade como um desafio, o que remete à necessidade de construçáo de uma gestão democrática, ilustrada pela fala de $\mathrm{OE}$ :

O aluno necessita estabelecer relações com as questôes da comunidade, profissionais e das relaçôes humanas [...] precisam aprender com a comunidade e que esta esteja na escola e a escola se insira na comunidade e que os alunos percebam como isso é importante no dia a dia [...] Esta grande dificuldade, muitas vezes faz com que o aluno perca a motivação de determinada disciplina, não percebe sua importância, não entende que isso faz parte do seu dia a dia.

Essa fala oportuniza reconhecer a importância da relação entre instituição escolar e comunidade, na perspectiva da inter-relaçáo entre as questôes sociais da comunidade local, não só do ponto de vista do ensino, mas da qualidade e potencialidade da sua transformação. 
Em relação à evasão dos alunos matriculados na $\mathrm{I}^{\mathrm{a}}$ série do Ensino Médio, entre os anos de 2007 e 2009, os participantes das entrevistas evidenciaram que as causas motivadoras da evasão escolar da $\mathrm{I}^{\mathrm{a}}$ série do Ensino Médio foram: dificuldade dos alunos de conciliar escola/trabalho; baixa participação e apoio da família; desinteresse dos estudantes; ausência de aulas práticas; baixos resultados/notas. Houve quem citasse, ainda, a desvalorização do professor.

As respostas contribuem de modo relevante no que concerne a esclarecer as dificuldades dos alunos de conciliaçáo entre escola/trabalho. Como podemos perceber, os entrevistados destacaram que os adolescentes/jovens do Ensino Médio enfrentam dificuldades para conciliar as atividades escolares e as responsabilidades requeridas pelo mundo do trabalho, por serem majoritariamente alunos do período noturno.

A maior evasão é na $\mathrm{I}^{\mathrm{a}}$ série do período noturno, durante o período diurno não se tem tanto. Os alunos trabalham durante o dia e cansados acabam se evadindo, por notas baixas, falta de tempo para fazer as coisas, náo sacrificam o final de semana para estudar e fazer trabalhos, isso tudo junto faz com que se desestimulem. No período diurno, se pegarmos os nossos relatórios, não temos tanta evasão, é um ou outro que acaba se evadindo por causa de notas. No terceiro bimestre, percebe que não conseguirá alcançar a média para passar, e acaba desistindo porque não consegue recuperar. (GEI)

Quando os alunos trabalham pela manhã ou à tarde frequentam a escola no contraturno, quando trabalham o dia todo o problema da evasão é mais acentuado. A evasão no noturno é em função do cansaço de trabalhar o dia inteiro e estudar a noite. $\left(\mathrm{P}_{2}\right)$

Torna-se notável o comprometimento do rendimento escolar dos alunos quando eles não sabem administrar a relação escola/trabalho. Para os entrevistados, o que provoca a evasão, em muitos casos, é o desinteresse dos adolescentes/jovens na escola depois de ingressarem no mundo do trabalho, que exige mais dedicação do que a instituição escolar. Atrelada à atenção destinada ao emprego, emerge a baixa frequência, refletindo em 
altos índices de faltas, baixo rendimento, notas baixas e, por consequência, desestímulo e evasão.

Para Abramovay e Castro (2003, p. 532), "no caso das escolas públicas, observa-se que os níveis de abandono são maiores no noturno”, confirmando a realidade expressa pelo depoimento e os estudo realizados pelas autoras no país. Para Küenzer (2007), esse é um problema recorrente nessa fase da vida dos adolescentes/jovens, porém, não pode continuar afetando o Ensino Médio, pois difere da finalidade da instituição escolar em todos os níveis de ensino, como fundamental instituição no processo histórico de eliminação das desigualdades. A autora chama a atenção para a responsabilidade das políticas públicas estarem atentas ao jovem, considerando suas especificidades, para enfrentamento da evasão e da repetência:

A melhoria das condiçốes de sucesso e permanência dos estudantes depende de uma série de investimentos, tendo em vista a qualidade do ensino: em equipamentos, em ampliação de espaços físicos, na qualificação permanente dos professores. Entretanto, nada será suficiente se não houver um rigoroso esforço na reconstrução da proposta político- pedagógica da escola, tendo em vista as demandas da educaçáo do jovem e da sociedade, em face da nova realidade social produtiva. (KÜENZER, 2007, p. 45)

Toda evasão escolar possui uma motivação e ocorre quando o adolescente/jovem deixa a escola por algum motivo, em determinando momento da sua escolarização. Para a mudança dessa realidade é eminente que todo o processo do ensino e da aprendizagem seja percebido como um caminho a ser percorrido por alunos e profissionais da educação juntamente com a sociedade, vislumbrando a conquista do conhecimento.

Por fim, a desvalorização do professor também é algo que aparece como causa da evasão escolar no Ensino Médio, como é possível perceber no depoimento que segue: "Eles vêm de uma família desacompanhada, desajustada socialmente e entram em uma escola com um professor que também passa por esse processo de "desacompanhamento" e desvalorização." (SE) 
Chegamos a um momento significativo da investigaçáo. Como em todas as questóes, a problemática da desvalorização do profissional da educação, em especial a do professor, aparece como situação alarmante no sistema educacional brasileiro. Em virtude dessa problemática, Abramovay e Castro (2003) destacam que a falta de interesse e de extrema insatisfação dos professores geram também a desmotivação nos seus alunos. Outros professores consideram que a instituição escolar não corresponde aos anseios dos adolescentes/jovens contemporâneos, fato que acentua a evasão escolar.

\section{Consideraçóes finais}

Os desafios da evasão escolar na I $^{\text {a }}$ série do Ensino Médio no município de Joaçaba, Santa Catarina, concorrem para a reafirmação do conservadorismo pedagógico recorrente da histórica divisão social do trabalho existente no Brasil. A pesquisa, no entanto, oportunizou a percepção de que existem possibilidades para o enfrentamento da evasáo escolar no Ensino Médio e a necessidade de políticas públicas efetivas para a educação nesse nível de ensino.

Os resultados da pesquisa corroboram a necessidade de investimentos públicos essenciais para uma educação pública de qualidade referenciada. Investimentos dirigidos à promoção de atividades intelectuais atreladas à produção de cultura, ciência e tecnologia, com vistas à construção da cidadania participativa e da preparaçáo para o mundo do trabalho, contribuindo, assim, para mudar a história de adolescentes/jovens com uma educação cidadã que valorize as experiências concretas dos alunos do Ensino Médio.

A oportunidade de vivenciarmos o conhecimento e percebermos sua aproximação com a realidade enseja a valorização do aprendido nos grupos sociais de que fazemos parte, problematizamos situaçóes, promovendo questionamentos e evoluindo na criticidade e nas intervençóes que transformem nosso contexto e contribuam para o desenvolvimento humano e social. Com críticas aos saberes eruditos produzidos histórica e socialmente, e com a valorizaçáo dos saberes sociais da atualidade, para o exercício da cidadania consciente. 
A pesquisa aqui apresentada está intimamente ligada ao real conhecimento das motivaçóes da evasão escolar no Ensino Médio, abrindo caminhos para uma atuaçáo rigorosa no enfrentamento dos desafios que a circundam. Nas entrevistas realizadas com distintos atores da realidade escolar, emana a necessidade de se definir, para o nível médio do ensino, uma concepção que valorize os contextos de onde os adolescentes/ jovens são oriundos, com processos de ensino e aprendizagem trabalhados na perspectiva do desenvolvimento humano e social e de preparaçáo do jovem para vida e para o mundo do trabalho.

O fenômeno da evasão escolar, de acordo com as respostas dos sujeitos, nos faz refletir sobre o cerceamento de sonhos e oportunidades com que deparam os jovens/adolescentes no âmbito escolar. Oportuniza reafirmarmos que o Ensino Médio carece de atenção das políticas públicas e de uma prática pedagógica atrativa, de qualidade social referenciada, para que não haja desestímulo em razão da necessidade dos estudantes de exercerem atividades laborais enquanto estudam, para que a escola náo acabe por colaborar para a desistência de parte significativa desses adolescentes/jovens.

Atrelada à atenção destinada ao emprego, emergem as faltas que geram a baixa frequência na escola e que resultam em pífio rendimento escolar, expresso no não alcance das médias para aprovação e, por consequência, no desestímulo e no abandono. A alternativa é o conhecimento sem censura ou qualquer tipo de preconceito que possa derivar para um enfrentamento demagógico e sem efeito qualitativo. Nesse sentido, temos que considerar o Ensino Médio como um nível de ensino que visa à formação, na contemporaneidade, de adolescentes/jovens polivalentes, e que propicie as condiçôes de possibilidade para a evolução do ser, contrapondo-se à visáo distorcida da necessidade do ter.

Para tanto, postula-se uma política educacional voltada ao acesso universal à educação, que possibilite permanência e qualidade social referenciada do ensino, pois assim haverá aprendizagem e democratização da escola pública. Ao valorizarmos nossos aprendizes, incitando-lhes ao exercício do pensamento, traçando diálogos trans-meta-disciplinares com os contextos contemporâneos, incentivando-os à construção de uma educação valorizadora do ser, do habitar e conviver nos novos espaços-tempos da sociedade. 
Valorizar o que os adolescentes /jovens já sabem, incentivando-os a interpretar a história e desenvolver o necessário discernimento político que leva ao efetivo exercício da cidadania consciente - nesse movimento, são transpostos o individualismo e a meritocracia para a valorização do que realmente importa ao desenvolvimento das potencialidades humanas. Asseguremos a permanência desses indivíduos jovens e adolescentes nas instituições escolares, que possibilitarão seu desenvolvimento pessoal e profissional.

\section{Notas}

I No ano de 2003 a $9^{\text {a }}$ Coordenadoria Regional de Educaçáo passa a se chamar Gerência de Edu-

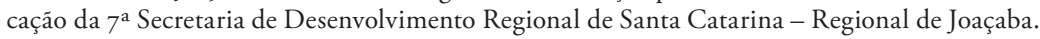

2 Neste artigo vamos nos referir aos alunos da primeira série do ensino médio como adolescentes/ jovens, por esses sujeitos estarem na faixa etária entre is e I7 anos, considerando esse o termo mais adequado para o tratamento desses alunos, enquanto cidadãos de direitos e deveres nesse nível de ensino, última etapa da Educação Básica.

3 Ruy Leite Berger Filho foi titular da Secretaria de Educação Média e Tecnológica (SEMTEC) do Ministério da Educação no período I995-2003

4 SANTA CATARINA, Secretaria de Estado de Educação e Desporto. Proposta Curricular de Santa Catarina: Educação Infantil, Ensino Fundamental e Médio: Disciplinas Curriculares. Florianópolis: COGEN, 1998.

5 SANTA CATARINA, Secretaria de Estado de Educação, Ciência e Tecnologia. Proposta Curricular de Santa Catarina: Estudos Temáticos. Florianópolis: IOESC, 2005.

\section{Referências}

ABRAMOVAY, Miriam; CASTRO, Mary G. Ensino Médio: múltiplas vozes. Brasília: UNESCO, MEC, 2003.

ARROYO, Miguel. Fracasso / Sucesso: um pesadelo que perturba nossos sonhos. Revista Em Aberto. Brasília, v. I7, jan. 2000.

BERGUER FILHO, Rui L. Apresentação. In: BRASIL. Ministério da Educação. Secretaria de Educação Média e Tecnológica. Parâmetros curriculares nacionais: Ensino Médio. Brasília: MEC / SEMTEC, I999.

FREIRE, Paulo. Pedagogia da autonomia: saberes necessários à prática educativa. $3 \mathrm{I}$. ed. São Paulo: Paz e Terra, I996.

FRIGOTTO, G., CiAVATTA, M. e RAMOS, M. (Org.). Ensino Médio integrado: concepçóes e contradiçóes. São Paulo: Cortez, 2005. 
GATTI, Bernadete A. Estudos quantitativos em educação. In: Educação e Pesquisa, São Paulo, v. 30, nI, p. I I-30, jan./abr. 2004.

INEP. Sinopse estatística da educação básica: censo escolar 2007. Brasília- DF, 2009.

KÜENZER, A. Z. Ensino Médio: construindo uma proposta para os que vivem do trabalho. 5. ed., São Paulo- SP: Cortez, 2007.

LASSANCE, A. Brasil: jovens de norte a sul. In ABRAMO, H. W. BRANCO, P. P. M. Retratos da juventude Brasileira. São Paulo: Ed. Fundação Perseu Abramo, 2005.

MANTOVAnini, M. C. Professores e Alunos Problemas: Um Círculo Vicioso. São Paulo: Casa do Psicólogo, 200I.

NERI, Marcelo. Motivos da Evasão Escolar. . Fundação Getúlio Vargas, Rio de Janeiro, RJ: 2009.

PATTO, Maria Helena Souza. A produção do fracasso escolar: histórias de submissão e rebeldia. São Paulo: T.A. Queiroz, 1996.

RIOS, T. A. Compreender e Ensinar: por uma docência de melhor qualidade. São Paulo: Cortez, 200I.

SACRISTÁN, Gimeno. O Currículo, uma reflexão sobre a prática. Porto Alegre: Editora Artmed, 1998.

Recebido em 29 abr. 2017 / Aprovado em I5 jun. 2018

Para referenciar este texto

CAMARGO, D. B.; RIOS, M. P. G. Evasão escolar na Ia série do ensino médio: o caso de Joaçaba, Santa Catarina. EccoS - Revista Científica, São Paulo, n. 46, p. 33-5I. mai./ago. 20I8. Disponível em: <https://doi.org/I0.5585/EccoS.n46.4287>. 
